Gramáticas de la (¿post?) violencia:

identidades, guerras, cuerpos y fronteras

\title{
Del ahogado el sombrero, a manera de manifiesto: esbozos para una crítica al discurso transicional
}

\author{
Alejandro Castillejo Cuéllar \\ ' Universidad de los Andes, Colombia
}

\section{Resumen}

Este texto-manifiesto es producto de mi trabajo de investigación y mi vinculación de largo aliento con organizaciones de víctimas de violencia en diversos lugares en el mundo. Plantea la necesidad de leer los "escenarios transicionales", sus discursos, presupuestos subyacentes y prácticas concretas, como parte de modelos globales de administración de los efectos de la violencia en contextos concretos: una intersección entre el dominio de lo global (los derechos humanos o los estándares internacionales de justicia, verdad y reparación) y su metamorfosis con teorías locales del daño. Este texto es entonces un destilado histórico, teórico y etnográfico sobre la noción de "transición", y sobre la experiencia de sociedades que aplican prácticas que buscan hacer un tránsito de la violencia (entendida de muchas maneras) a la llamada postviolencia.

Palabras claves: Estudios Críticos; Transiciones Políticas; Etnografía; Manifiesto; América Latina. 


\section{Del ahogado el sombrero, sob a forma de de manifesto: esboços para uma crítica ao discurso transicional}

\section{Resumo}

Este texto-manifesto é o produto de meu trabalho de pesquisa e de meu vínculo de muitos anos com organizações de vítimas de violência em diversos lugares no mundo. Reivindica a necessidade de ler os "cenários de transição", seus discursos, pressupostos subjacentes e práticas concretas como parte de modelos globais de administração dos efeitos da violência em contextos concretos: uma interseção entre o domínio do global (os direitos humanos ou os padrões internacionais de justiça, verdade e reparação) e suas metamorfoses com teorias locais do dano. Este texto é assim um destilado histórico, teórico e etnográfico sobre a noção de "transição" e sobre a experiência de sociedades que aplicam práticas que buscam fazer um trânsito entre a violência (entendida de muitas maneiras) à chamada pós-violência.

Palabras-chave: estudos críticos; transições políticas; etnografia; manifesto; América Latina. 


\title{
Del ahogado el sombrero, a manera de manifiesto: esbozos para una crítica al discurso transicional
}

\author{
Alejandro Castillejo Cuéllar
}

Este texto es producto de mi trabajo de investigación y mi vinculación de largo aliento con organizaciones de víctimas de violencia en diversos lugares en el mundo. ${ }^{1}$ Plantea la necesidad de leer los "escenarios transicionales", sus discursos, presupuestos subyacentes y prácticas concretas, como parte de modelos globales de administración de los efectos de la violencia en contextos concretos: una intersección entre el dominio de lo global (los derechos humanos o los estándares internacionales de justicia, verdad y reparación) y su metamorfosis con teorías locales del daño. Este texto es, entonces, un destilado histórico, teórico y etnográfico, sobre la noción de "transición" y sobre la experiencia de sociedades que aplican prácticas que buscan hacer un tránsito, de la violencia (entendida de muchas maneras) a la llamada postviolencia.

Comienzo este breve escrito con una viñeta de mis diarios de campo sobre las continuidades históricas de la violencia y sus actuales lugares del terror en el puerto de Buenaventura, recabados durante los últimos años 4 años en paralelo al Proceso de Paz que se gestó en La Habana. ${ }^{2}$ En ese contexto, desarrollo, en las siguientes dos secciones, una crítica general al concepto de transición. En el primer apartado, a manera de "manifiesto," intento plantear una pregunta en voz alta, teniendo como centro de reflexión indirecto el contexto latinoamericano. A renglón seguido, en el segundo apartado, desarrollo las implicaciones de esta crítica y aclaro algunos de sus elementos. En el apartado tercero, planteo la manera cómo esta mirada interpela las ciencias sociales y la antropología como disciplina. Y finalmente, en una última viñeta, retorno a las paradójicas concreciones de la transición, y de la promesa de una nueva sociedad imaginada incrustada en el sueño desarrollista de un gran puerto en Urabá antioqueño, en Colombia. Las dos viñetas están íntimamente conectadas.

\section{Primera viñeta: el terror como forma de gubernamentalidad (...)}

Esta región en Colombia inevitablemente me recuerda el Chocó (la Serranía del Baudó, donde hice mi primer trabajo de campo como estudiante), mi paso de unos años por el Southern Africa, la vida en la Cape Town de Gugulethu y Grassy Park, y las conversaciones con mis amigos refugiados del genocidio en Ruanda con quienes vivía en un pueblito cerca de la imperial Viena. Me recuerda la Maison d'Esclaves en Dakar, la inexplicable nostalgia que siento por el Congo y por Angola (lugares donde nunca he estado físicamente pero que he leído y oído a través de otros), y claro, La Habana, siempre presente con su ausencia. Siempre llego a esta misma idea: ¿cómo se puede retornar a aquellos lugares donde nunca se ha estado, pero que se conocen íntimamente?

\footnotetext{
1 Algunas de estas ideas fueron expuestas como parte de una de las conferencias centrales en el Foro Central "Guerra y Academia”, Congreso de la Asociación Latinoamericana de Antropología (ALA), Universidad Javeriana, Bogotá, Junio 5 de 2017. La metáfora del título es un dicho popular en Colombia que hace referencia al ideal según la cual frente a la catástrofe (en hecho de que alguien se ahogue) hay que conformarse (en una mezcla entre resignación y humor) con lo que quede, pues al menos ha sobrevivido algo (el sombrero). Nos ha quedado pues un rastro de algo, de lo que ya no está. El sombrero metaforiza el cuerpo, la persona, o en el caso de este ensayo, lo que nos queda de la promesa de la transición es un sombrero.

2 Al momento de escritura de este artículo el Acuerdo pactado en La Habana se ha convertido en una compleja transmutación, pasando por la derrota del plebiscito que buscaba refrendarlo y por su casi fracasado paso por el Congreso de la República. A ese acuerdo le llamo el Acurdo de La Habana-CartagenaTeatro Colón.
} 
Todos estos lugares están interconectados en el tiempo: descendientes de seres humanos esclavizados, todos herederos del tráfico de cuerpos, llenos de historias de destitución que cohabitan con grandes sagas de resistencia y sobrevivencia. Mar turbio, el Pacífico, potente, e intransigente.

Notas de Campo (modificadas), mayo del 2016

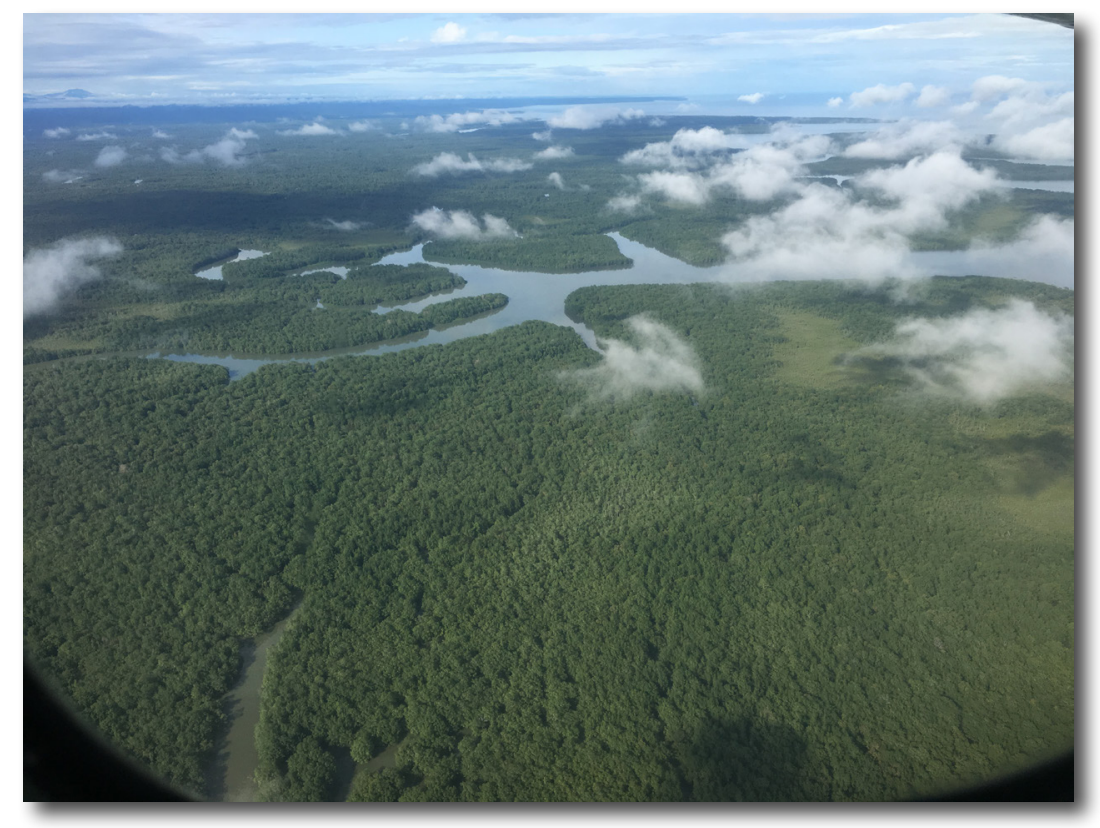

Hace un tiempo asistí a la presentación de una obra de teatro organizada por grupos de jóvenes de las barriadas de Buenaventura. Era en el marco de un encuentro de organizaciones de desplazados provenientes de las zonas rurales. Querían discutir el impacto del proceso de negociación de La Habana en esa región. Yo, a la vez, aproveché también para visitar de nuevo el Espacio Humanitario en Buenaventura, Puerto Nayero $^{3}$, donde había estado en varias ocasiones. La obra me conmovió profundamente. Los veía en medio de la oscuridad deslizando sus historias esa noche. Era como una especie de testimonio colectivo, puesto en escena, realizado con su cuerpo, en su cuerpo. ¿Quién ha dicho que el testimonio es solamente esa articulación de la experiencia que se realiza oralmente? Aquí la marimba se entretejía con su cadencia nostálgica y con las voces de esas mujeres que arrastraban los alabaos desde el mismo Chocó. ${ }^{4}$ Elogio a la supervivencia y la creatividad de la vida.

Como siempre, me encontré, de nuevo, con historias pequeñas de grandes heroísmos, de mujeres que le han puesto el pecho a la violencia. Fue escalofriante escucharlas: la crítica constante al "modelo de desarrollo" se realizaba desde su experiencia vital (con la profundidad personal e histórica que eso implica para un hombre o una mujer afro) pero con superficialidad repetitiva, aunque claramente disonante del discurso oficial de la "construcción de paz" y sus filiales académicas: las mismas que jamás dejan las oficinas de las universidades y presumen que el trabajo de campo se asimila a una forma de turismo humanitario. Fue escalofriante porque la paz parecía otro planeta. Fue escalofriante por la vulnerabilidad de esta gente ante el argumento estatal en el que el desarrollo se concebía como consecuencia sine qua non

\footnotetext{
3 Buenaventura (Departamento del Valle del Cauca) es el puerto marítimo más grande de Colombia, localizado en el Océano Pacífico. A través de él pasa la mayoría de las importaciones marítimas del país. Una región de selva tropical húmeda y biológica que atesora kilómetros de bosques, maderas finas y minerales estratégicos. Territorios colectivos de comunidades negras y resguardos indígenas. Históricamente, región de esclavos liberados, y ciudadanos excluidos. El Espacio Humanitario es una calle en esta ciudad que ha sido retomada por la población, expulsando de ella actores armados a través de una demarcación social y espacial.

4 Departamento de Colombia, capital Quibdó. "Alabaos" hace referencia a la música y coros populares de la región, cantados durante novenarios y velorios: https://www.youtube.com/watch?v=NX49kxCYG6M, https://www.youtube.com/watch?v=uenxrggiBPM
} 
de la paz (lo que eso quiera decir). Los proyectos de desarrollo y sus efectos conformaban el precio que se debía pagar por la paz. Y efectivamente, allá están las empresas, disfrutando de las mieles. Y en la mitad, estas personas, habitando lugares en los que no deberían estar, "obstaculizando", como se escucha con frecuencia, el porvenir. Cuántas veces he escuchado a la Colombia mestiza, la misma que era detenida en los aeropuertos del mundo por traficante, decir que los mundos indígena y negro eran obstáculos para el desarrollo.

Esta zona de Colombia es la intersección de múltiples violencias: la del conflicto armado, al que después de décadas del desplazamiento de cientos de familias se le suma la indiferencia estatal militarizada y la miseria que transmuta desde los tiempos de la colonia, la de los acumuladores de riqueza crónicos, politiqueros corruptos, taladores de bosques (legales e ilegales) y traficantes de todos los pelambres (legales e ilegales). Traficantes de niños y jóvenes, de cuerpos de mujeres que, de Panamá a Chile 5 son vistos como reminiscencias de las Venus extraídas del África en el siglo XIX, como Sara Bartmann, destinadas a ser vistas como "putas" o parte de freak shows ambulantes. Traficantes de objetos, de armas, de sustancias, de animales, de plantas (es más, de la selva tropical húmeda en su totalidad), de ideas, de patentes, de influencias y hasta de sueños: todo polizón es un soñador secuestrado por su sueño. En ese momento, evidencié lo que llamaría la violencia de la post-violencia, la del llamado "desarrollo", que viene acompañada de una larga historia de desapariciones forzadas, donde los ríos y la costas mismas son grandes fosas comunes, cementerios acuáticos de restos sin nombre. La violencia que la transición hace invisible y que las legislaciones en la era de las víctimas considera superada. Los chicos que vi me recordaron ese palimpsesto que es el daño. A mi modo de ver, la Costa Pacífica es el laboratorio de la llamada transición colombiana: la que se vende rimbombante en camino "hacia un nuevo futuro", la del polo de desarrollo hotelero y turístico (no obstante sus contaminadas aguas), la de la "biodiversidad" (raponeada o arrebatada a la fuerza), la de la "diversidad cultural" (abandonada), la de la globalización contemporánea. Para estas organizaciones, la promesa transicional no es una ruptura con la violencia, sino más bien una continuidad histórica.

En medio de todo esto emerge, hace unos pocos años, un Espacio Humanitario, construido poco a poco por desplazados que salieron de Puerto Naya, en Nariño, un lugar lastimosamente conocido por una masacre. El lugar, asimismo, constituía un territorio "rescatado al mar" a punta de rellenos de rocas, escombros y basuras, una pequeña extensión del continente que engulló el mar para recrear una extensión de las "territorios colectivos" afrocolombianos reconocidos por la Ley 70 y de donde muchos habitantes provenían. ${ }^{6}$ Puerto Nayero representa la venida del monte a la ciudad, a una costa ahora en disputa con constructores y sus proyectos hoteleros. El sector se extiende por una sola calle, rodeada de secciones llenas de pequeñas moradas en madera y levantadas a la manera de palafitos, una construcción tradicional en zonas acuíferas. No hay sistemas sanitarios ni aguas potables y la insalubridad es rampante. Un amigo camerunés me contó (quizás exagerando para mostrar su asombro) que cuando pasó por Buenaventura había pensado que ni en el África había visto semejante destitución. Claro, excepto los países en guerra, como el Congo o Liberia, o algunos shanty towns o tugurios en Lagos o Johannesburgo. Exageraba. Puerto Nayero está rodeado de barrios atestados de grupos armados: neo-paramilitares, micro-traficantes de droga, mercenarios o sicarios, fronteras imaginarias entre combos o pandillas configurando una verdadera cartografía del miedo. Algunos hasta dicen que las maras salvatruchas han estado entrando con dificultad. Jóvenes deambulando por todas partes, chicos sin otro destino que las economías ilegales.

\footnotetext{
Esta referencia se la debo a mi colega Margarita Echeverri.

6 LEY 7o DE 1993 (agosto 27) Diario Oficial No. 41.013, de 31 de agosto de 1993, por la cual se desarrolla el artículo transitorio 55 de la Constitución Política, que "tiene por objeto reconocer a las comunidades negras que han venido ocupando tierras baldías en las zonas rurales ribereñas de los ríos de la Cuenca del Pacífico, de acuerdo con sus prácticas tradicionales de producción, el derecho a la propiedad colectiva, de conformidad con lo dispuesto en los artículos (...)”.
} 
En este mundo, las historias de horror se multiplican: el océano pacífico, turbulento y oscuro, es una gran fosa común, donde las gentes se amarraban muertas y vivas en travesaños enterrados en el piso del mar, durante marea baja, para que luego la subida los hundiera en el olvido. Sabemos del impacto en la identificación de cuerpos podridos en el agua.

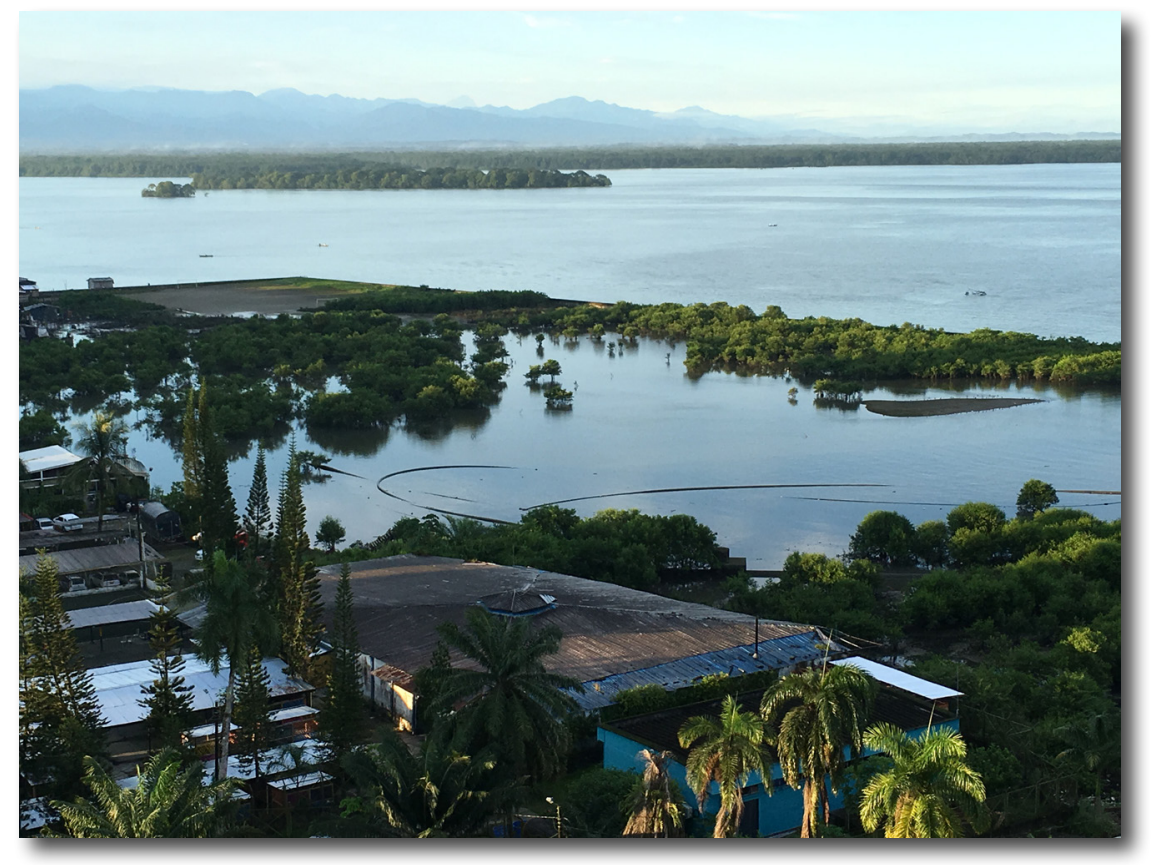

En medio del proceso de La Habana, se dio una racha de violencia sobre las gentes que vivían en esas costas. La indiferencia del Estado en todo eso fue total hasta el extremo. Al final, la respuesta institucional ante la presión social fue la militarización de la ciudad, y en particular, de algunos sectores. La estabilización de esa zona del país era indispensable para el Presidente, quien había basado su política económica en las industrias de extracción y en las agriculturas industrializadas, y por supuesto, la colonización de las zonas antes dominadas por las FARC-EP. Era inevitable para mí conectar eso con la expoliación europea del África a finales del siglo XIX, y por supuesto, imaginar una conexión costera con México o América Central y los grandes cinturones de Maquilas. Por eso existe, en este escenario de transición, una terrible contradicción entre el proyecto económico y lo que con frecuencia el Estado llama la "financiación de la paz" (lo que eso quiera decir). Estamos sembrando la semilla de viejas nuevas guerras. La necesidad de vender la región, de mostrar a través de videos propagandísticos que "Colombia, Magia Salvaje” esta "open for business", en la Amazonía, la Serranía de la Macarena, en la misma región del Chocó, o en el Guainía. Lo último que se necesitaba era hacer público que había regiones que podían poner en peligro la llamada "confianza inversionista".

En este contexto, el terror se convirtió en el principio rector de orden social; el terror como forma de organización. Cuando hablo de terror, me refiero a la colonización de la vida cotidiana por la incertidumbre y la muerte, administrada incluso aleatoriamente; a la fractura de las "estructuras del mundo de la vida"; a sus corporalidades, espacialidades y formas de enunciación (Schutz \& Luckmann, 2003). El mundo se convierte esencialmente en alteridad radical. El discurso de la transición es, no una forma de gobierno codificada en los términos "justicia, verdad y la reparación", sino una administración de la frontera entre la 
vida y la muerte, una forma de "gubernamentalidad" centrada en la desprotección estructural (mi término) e indiferencia estratégica Fue en el seno de la instauración de un "escenario transicional", como lo definiré más adelante, a través del cual el terror, por indiferencia, se incrustó en esas vidas de nuevo.

La figura más macabra de ese terror transicional (que es distinto al terror de la violencia política), de su banalidad y de su gratuidad aparente (en sí misma una forma de mensaje, de contenido densificando en la forma) es la casa de pique. ${ }^{8}$ Había recolectado historias de estas "casas" en alguna otra ocasión, en el Espacio Humanitario, precisamente. Esta Zona lleva su nombre porque, centímetro a centímetro, fue rescatada de los violentos, sacando a todos de sus alrededores. Una especie de circunspección espacial, un cerramiento zonal, con la entrada a un lado, demarcando el acceso con una gran puerta vigilada 24 horas por un policía adormilado y el mar, en el extremo opuesto. Junto con algunas organizaciones que acompañaron los primeros momentos del proceso, en el período de dos años, lograron establecer esta isla en medio de un archipiélago de desesperanza. En este lugar, no obstante las enormes limitaciones, los niños corretean de arriba a abajo, fuera del control y la vigilancia de las pandillas que presionan y amenazan todos los días. Recuerdo cuando Oscar, uno de sus líderes, me cuenta que tenía encima más de veintiséis amenazas de muerte.

El evento centrípeto que, como un agujero negro, dio origen a este experimento humanitario fue, precisamente, una casa de pique (porque ha habido muchas). Se le llaman así porque eran lugares donde, en la noche, se descuartizaban o se picaban a las personas (como cuando se "pica" un tomate o una cebolla, en trozos pequeños antes de cocinarlos) y cuyos restos, a veces ahí mismo desde el palafito, eran botados al mar. "Mataderos", "botaderos", "escombreras" o "asustaderos" (el término es mío), cuerpos violentados en medio de la transición, en medio de la instauración de mecanismos de "post-violencia": esa era la cara más evidente de la violencia de la post-violencia. ${ }^{9}$ No voy a negarlo: ninguno de estos eventos capturaba seriamente la imaginación antropológica (ni de las ciencias sociales). Todo lo contrario. Si hay una disciplina particularmente ausente de las decisiones nacionales, de los debates sobre el porvenir era -y sigue siendo- la antropología.

Podría sumar los fragmentos de entrevistas, diálogos y conversaciones que tuvimos con diferentes personas allá, durante los últimos años. Pero quizás el momento más iluminador, que conecta las geopolíticas de la expropiación (es decir, la rapiña global de tierras) y las micro-políticas de la muerte, fue la percepción de la casa de pique misma. En ese viaje mi intención, entre otras, era realizar una serie de grabaciones en audio del lugar, parte de un esfuerzo creativo (por ponerle un nombre a esa necesidad de convergencia entre las artes de la supervivencia, las ciencias sociales, y la denuncia) de leer la violencia y sus rastros desde lo sonoro, una especie de historia y etnografía sonora de la guerra y la memoria, con miras además a una casa de la cultura que queríamos ayudar a construir en un lote-basurero. Al final, los tiempos de la muerte y la pobreza, aunados al robo literal de las entrevistas, lo truncan todo o lo hacen aplazar.

\footnotetext{
8 Mi intención, con estas salidas de campo, era triple: además de medirle la temperatura al Proceso de Paz (cuestión que llevaba haciendo por casi tres años en diversas regiones del país) quería conformar un laboratorio de seguimiento a la transición desde allí, desde el punto de vista de la región. Además, quería colaborar en procesos comunitarios con el conocimiento que tenía de otros procesos de transición. Esto, bajo la convicción de que las críticas más sólidas al proyecto transicional y su gubernamentalidad neoliberal provenían de organizaciones y comunidades indígenas y negras. Por último, tenía un interés concreto en estudiar las formas contemporáneas de la desaparición, que no son necesariamente forzadas, en el sentido tradicional de la palabra.

9 Unos meses después estaría recorriendo esa montaña de cuerpos (haciendo una paráfrasis de Walter Benjamin) conocida como La Escombrera, en Medellín. Otro "botadero" de las violencias entre bandas de criminales, paramilitares, y agentes del Estado.
} 
Esto hacía parte también de un estudio que continúo realizando, sobre la figura del desaparecido en medio de una transición. A ese seguimiento, a esta erupción analítica de las dimensiones sociales de ausencia, le he llamado "la vida social de la búsqueda". ${ }^{10}$

Saqué esa tarde la grabadora. Llovía mucho, muchísimo, como suele llover en una de las zonas de mayor pluviosidad del mundo: 22 mil milímetros de agua al año. Mientras mi colega hablaba con doña Lidia, yo me encargaba de escuchar las gotas cayendo sobre la tierra y la fiereza de ese invierno sobre los tejados de zinc. Pegado al micrófono y a unos pequeños audífonos, mi oído pendulaba entre la lluvia y la conversación sobre Puente Nayero. Me moví unos metros y ante la casa de pique no pude más que imaginar lo que serían los sonidos de la muerte, pero no de cualquier muerte. No era precisamente el sonido de la última bocanada de aire antes de dejar este mundo. Pensé, de nuevo, en esa dimensión sonora del horror. Si hay una intuición, que emergió durante mi trabajo de campo en los asentamientos de desplazados en los años gos, fue la dimensión sensorial de ese horror. Escuché decenas de historias y testimonios con gritos, risas, palabras, pájaros, vientos, tarareos de balas, gemidos animales, expresiones de sentimientos y onomatopeyas orales. Las entrevistas son textualizaciones del fenómeno sónico. También son textualizaciones del fenómeno táctil o háptico. Recuerdo oyendo (en medio de la Cartagena paramilitar de aquella época) sensaciones de calor, de frío, de miedo hecho vómito y heces, que avasallaban el cuerpo de Don Jorge sobre el piso (haciéndose el muerto), mientras los verdugos, en plena plaza pública, asesinaban a sus vecinos y su sangre tibia corría por su brazo. Pensé, de manera irresponsable, cuáles serían los sonidos de la casa (ambos, el lugar de la muerte y el lugar de la familia), cuáles los gritos en ese lugar de cambuches de madera donde la filtración del sonido era inevitable y hasta amplificable. Una especie de morbosidad sacrílega capturó mi imaginación. Estaba en ese espacio microscópico habitando los tiempos de la reconciliación, a la vez que caminando entre los lugares de la violencia de la post-violencia. La pregunta que me queda es ¿dónde trazamos la línea entre el pasado, el presente liminal, y el futuro por venir? Qué distinta se lee o se advierte esta línea imaginaria desde diferentes lugares. En el Pacífico, pareciera que la transición fuera simplemente otro capítulo más de terrores ancestrales.

\section{La reinscripción del Estado sobre sí mismo}

Diversos autores han planteado que la idea de "promoción de la democracia", y sus corolarios, y el establecimiento de un "paradigma transicional" hacia la democracia, son artefactos propios de las configuraciones políticas e intelectuales, producto del derrumbe del imperium soviético y la hegemonía de la llamada paz del vencedor (Carrothers, 2002; Bhta, 2008; Guilhot, 2005:29; Castillejo, 2016b; Letham, 2003). El fin de la guerra fría y el realineamiento estratégico vino incluso de la mano de la conformación de lo que podríamos llamar las "ciencias" del Estado, o la Ciencia Política, en singular: programas académicos

\footnotetext{
10 En la medida en que el estudio de los "escenarios transicionales", como lo plantearé más adelante, se centre en los dispositivos que constituyen este paquete tecnológico que llamamos transición-a-la-post-violencia, la expresión la vida social de la búsqueda hace referencia a la serie de espacios sociales, sus interrelaciones humanas y no-humanas concretas, sus prácticas cotidianas, sus mundos-de-la-vida, y las formas de producir saberes expertos que entran a formar parte del proceso de búsqueda, localización e identificación de un desaparecido. Son complejos archipiélagos de conocimientos (el de los familiares, el de los arqueólogos y antropólogos forenses, los abogados, los biólogos, etc.) donde la ausencia misma emerge como "objeto" legal, técnico-científico (a través intervenciones, como de bases de datos o laboratorios), onírico, estético y sujeto de duelo, entre otros. El término búsqueda, pues, indica la manera en que la ausencia es encuadrada por todos estos modos de hacer y modos de enunciar. Las preguntas más obvias pierden naturalidad, con el objeto de entender no sólo las tensiones entre pasado, presente liminal, y porvenir, sino los recursos que una sociedad tiene para hacer inteligible lo que de otra forma parecería ininteligible: ¿qué es buscar, en qué espacios se busca: oníricos, científicos, geográficos, discursivos? ¿Qué es encontrar? ¿Qué se encuentra y qué se busca exactamente? ¿Cómo quedan, se recogen y se leen rastros en tanto rastros? ¿Qué es un rastro? ¿Quién busca y quién encuentra, y quién acoge lo encontrado? ¿A través de qué tecnologías, de qué lenguajes, de qué objetos, de qué sensorialidades? ¿Cuándo se deja de buscar? Y, ¿si nunca se deja de buscar lo ya encontrado? En el libro "Tras los rastros del cuerpo: etnfonías, (in)materialidades, y la vida sensible de la desaparición en Colombia" me embarco en esta "etnografía de la ausencia” estudiando los espacios habitados por ella, pero vertebrando la investigación a través de sus disensiones sónicas (ante la sensación abismal que las palabras en ocasiones me producen). Para más elementos sobre la vida social de la búsqueda, puede verse sobre las apropiaciones estatales de apropiación del daño, Castillejo (2017b); sobre los grupos de búsqueda, Castillejo (2014); y sobre las lógicas legales y las confesiones, Castillejo (2013).
} 
en política pública (en inglés también public policy o policy studies) centrados en las administraciones del poder estatal y los diseños de las sociedades, casi a la manera de la "expertocracia" (hoy llamaríamos "gobernanza" y "buenas prácticas") propias del período colonial en el África del siglo XIX (Demmers, Fernandez, Hogenboom, 2006; Chandler, 2006). Todo esto, presentado como parte del pináculo de la ciencia y la civilización (Gilman, 2003; Abrahamsen, 2000; Anghie, 2004; Keene, 2004)."

Adobado con la institucionalización de "las multinacionales de lo humanitario", algunas veces llamadas organizaciones no gubernamentales, y el discurso redentor y globalizado de los derechos humanos (y la multiplicidad de agendas que se le injertan), las ideas de democracia y de paz se sitúan como una teleología en sí misma, como figura mesiánica y emancipadora del sujeto libre y soberano para delegar su capacidad de decisión (Guilhot, 2005:166; Parekh, 1993;). No obstante, para nadie es un secreto que, de cara al poder establecido y a la guerra indefinida, de cara a la desolación y al abuso, la defensa de los "derechos humanos", parte de los lenguajes de la Estatalidad, son el elemento central de "nuestras" formas de acción, para mal o para bien. Ante la dictadura, el conflicto armado, o el racismo institucionalizado, la "promesa" de una nueva nación parece encarnar una revolución. ${ }^{12}$ Ante el hambre, un grifo de agua potable y un "salario" básico, que permita una ingesta mínima calórica, parecen una revolución. Ante la destitución crónica, una migaja es supervivencia.

Tomando en cuenta el anterior descargo de responsabilidades, me atrevería a decir que en este momento, producto del desprestigio de utopías fracturadas, liquidadas y desaparecidas, desprestigiadas o mediocres, comunitaristas o individualistas, tecnológicas o sacralizantes, hemos canjeado el sueño de una otra sociedad por una "promesa" tecnocrática y domesticada que llamamos "transición a la post-violencia". Sabemos que esta "tecno-política" implanta una imagen futura de la sociedad y sus sujetos, creando "una línea imaginaria entre el pasado, el presente liminal y el futuro porvenir” (Mitchell, 2002; Castillejo, 2017a). Hace hincapié, en su arquitectura conceptual y en los valores que persigue a través de sus instituciones, en una ruptura con las violencias pasadas (las que son legibles o nominables), antes que en sus continuidades. Es a través de la implantación de lo que llamo el "evangelio global del perdón y la reconciliación", que emerge el futuro como posibilidad, una relación con el pasado, una concepción del daño y su transmutación social: un intento por "remendar" la sociedad. ${ }^{13}$ En otras palabras, la transición instaura una epistemología particular.

11 Este párrafo, en cierta forma derivado de Foucault, evidentemente invita a una relectura de la relación entre geopolítica (es decir, entre el espacio y el poder) y las ciencias sociales (Ó Tualhail, \& Dalby, 1998). Más que un decantado propio de la evolución del pensamiento (donde unas teorías, pensadores y comunidades de sentido son superadas por otras más avanzadas), el origen de conceptos (tal y como el concepto de "promoción de la democracia", "estudios de área" o "modernización política" en el inmediato período postcolonial en el África) obedecen a conversaciones situadas en complejos campos de poder. Quizás en antropología es más emblemático el concepto de "tribu” y su centralidad en el proceso de dominación británica en África. La pregunta por las transiciones y por la democracia neoliberal como teleología invita a pensar esos campos de poder que instauran -desde la academia, los fondos de investigación, y la llamada incidencia política de ONGs- una visión de la sociedad, del futuro y del pasado como legitímos (González, 2010; Nugent, 2010; Doornbos, 2006).

12 Para ponerlo en otras palabras: en qué momento "promover" la democracia se cristalizó en el lenguaje de la defensa de los derechos humanos. Dicha defensa, como lo muestran la historia de las transiciones a la democracia en América Latina, constituye el lenguaje de la sociedad contra la dictadura. Sin embargo, viene la pregunta compleja: ¿en qué momento y cómo, de cara al paradigma de las transiciones (que instaura una forma de estatalidad), dicha defensa y dicho discurso se hace instrumental a un poder establecido (el de los beneficiarios de la violencia), haciéndolo incluso retardatario y conservador? La transición sudafricana, por ejemplo, fue a la vez un salto monumental (acabar con el racismo legalizado y la indigencia social que promovía) y la solidificación de los beneficiarios del mismo racismo legalizado.

13 Aquí, como en otros textos, retomo la genealogía que conecta las palabras "enmendar", "remendar", o incluso "enmienda": el verbo Emendare del latín ("corregir las faltas"), se traduce también como "remediar", "mejorar" o "perfeccionar". Derivado de menda y mendum (falta, error, o defecto) de donde provienen términos como "mendigo". Del diccionario de la Real Academia de la Lengua Española, enmendar en sus densidades semánticas significa: 1. arreglar, quitar defectos, 2. resarcir o subsanar daños, y 3. variar el rumbo (según la necesidad). Cuando se habla de los efectos de la violencia y de lo que requerimos para sobreponernos se usa, en español, una variedad de términos y metáforas médicas, mecánicas o textiles subyacentes: reconstruir (algo roto o dañado), sanar, curar o suturar (una enfermedad o una herida), tejer algo desanudado (la trama y la urdimbre) o restituir (el lazo o tejido social), etc. Aquí quisiera usar una más local, si se quiere: remendar (la sociedad) es mendar de nuevo los lazos en espíritu de futuro. Una metáfora textil, que junta lo desjuntado, que no se queda en la cicatriz, sino que la lleva consigo, donde se le nota la costura, el tejido, el hilo (en toda la obviedad del término "remendar") pero que no se queda en ese momento sino que, como "enmendar", fragua el cambio de rumbo, un nuevo destino, y un nuevo porvenir. 
Las críticas más acérrimas a la paz liberal, del tipo Banco Mundial, no provienen de la academia, que por lo general es más bien sumisa u orgánica a la racionalidad del diseño (Munarriz, 2008). En últimas, en el tsunami transicional, todos buscan trabajo, la financiación de sus proyectos de intervención, figuración política, o conversión al circuito internacional de consultores bien pagos que extraen la receta de las "lecciones aprendidas" en alguna esquina del sur global para aplicarla a otra, aún en "estado de barbarie". De hecho, la crítica proviene de los más desposeídos, de los que recuperan territorios del mar a punta de sacos de basura y escombros, de los que buscan a sus seres queridos, de los que se preguntan por "la violencia de la post-violencia”. De aquellos para quienes los ríos o las maderas no son bienes canjeables en el mercado internacional; que han padecido incluso el llamado "desarrollo" en función de la unidad imaginaria de la nación. De allí provienen las expectativas y las esperanzas, no de las comodidades teóricas y empíricas. De cara a esto, el reto del futuro no recae en la reinscripción del Estado sobre sí mismo, ni en los combates mezquinos (que algunos llaman "política" y que se dedican a modelar el disenso aceptable) sobre su propiedad. Otros lugares y otras voces me permiten dudar de este presupuesto organizativo. En últimas, como dijera Walter Benjamin, "todo documento de la civilización es también un documento de la barbarie". De esas otras voces, me queda la paz como el proyecto de "restitución de la projimidad del otro". ${ }^{14}$

Finalmente (para matizar esto con relación a Colombia), hay que diferenciar la crítica a la paz (y por ende, a la idea de transición) hecha desde aquellos que, contrario a lo pensado, son nostálgicos del Estado policial que se encarga de militarizar la frontera entre el mal y el bien absolutos. Esa llamada "crítica" no es "crítica"; son variaciones sobre un tema del poder y los privilegios concretos. ${ }^{15}$ La "crítica", por otro lado, implica no sólo la creación de otras discursividades, por extrañas que parezcan, sino una suerte de "activismo teórico" aunado, indeleblemente (y para que quede bien claro), a una suerte de epistemología colaborativa e itinerante que pone a prueba sus presupuestos al moverse. La crítica es adquirir una voz, en toda la complejidad de este término, y asumir un riesgo: es una mirada al fondo del abismo. Lo paradójico, sin embargo, es que la presencia del otro es la condición sine qua non para la articulación de una voz propia. Esto es, precisamente, lo que implica pensar en una "crítica" a los discursos de las transiciones.

\section{Deshilachando las Transiciones}

Una crítica al discurso y a las prácticas asociadas a las transiciones, y su imaginario de la ruptura, tendría que comenzar reconociendo que, en el contexto del mundo contemporáneo, estamos abocados a coexistir con múltiples formas de violencia y diversos modos de habitar la "academia". Para ponerlo en otras palabras, pareciera que asistimos a un momento donde el terror, como forma de gubernamentalidad (y aquí pienso en la metástasis que recorre medio continente, desde los botaderos y "asustaderos" de Buenaventura en Colombia hasta los vertederos de Tijuana en México) coexiste con diversos modos institucionalizados de la administración del dolor colectivo (paradójicamente constitutivos del discurso de la transición) a través de leyes de víctimas, programas de reparación del "daño", y comisiones de verdad incrustadas en "democracias" neo-liberales.

\footnotetext{
14 La frase hace referencia al debate en torno a dónde se sitúa el prospecto de la construcción de la paz, particularmente después de conflictos armados. Diversos autores lo ubican en la instauración de la llamada institucionalidad (o instituciones del Estado), una perspectiva "de arriba hacia abajo". Otros, por el contrario, adoptan una perspectiva menos jerarquizada, "de abajo hacia arriba”. Desde mi perspectiva, la restitución de la projimidad del otro plantea que los grandes retos de la paz van a localizarse en las interacciones cotidianas, que permiten la reproducción de lo social. En su seno, se configuran nuevas relaciones cara a cara que fracturen el orden militarizado de la guerra y la violencia, en el centro de lo que llamo la paz a pequeña escala, o la paz en plural (Richmond, 2010; Sriram, 2007).

15 Aquí la referencia está directamente relacionada con el plebiscito por la paz en Colombia, donde los "críticos" del proceso de Cuba lograron frenar su refrendación (Castillejo, 2016a).
} 
En este sentido, con esto como telón de fondo, quisiera plantear que la labor de la crítica puede girar en torno a las socialidades que emergen en lo que llamo "escenarios transicionales", es decir, "la serie de espacios sociales (y sus dispositivos legales, geográficos, productivos, imaginarios, epistemológicos, y sensoriales) que se gestan como producto de la aplicación de leyes de unidad nacional y reconciliación. Estos "escenarios" se caracterizan por una serie de ensambles de prácticas institucionales, conocimientos expertos y discursos globales, que se entrecruzan en un contexto histórico concreto, con el objeto de enfrentar graves violaciones a los derechos humanos y otras modalidades de violencia" (Castillejo, 2015:13) En otras palabras, son las socialidades que emergen de la tecnocracia transicional y las que emparentan contextos muy diversos susceptibles de indagación etnográfica.

Quiero entonces proponer una lectura particular de estas socialidades. La idea de una justicia transicional (un término altamente codificado) y la compleja red de mecanismos legales y extra-legales responsables de ocuparse de las causas y los efectos de graves violaciones a los derechos humanos, está basada en al menos dos presupuestos básicos. Por un lado, está fundamentada en la "promesa" salvífica o el "prospecto" de una nueva nación imaginada. La propaganda institucional en Colombia, "todos por una nueva nación”, es evidente en este sentido. En segundo lugar, en una inflexión simultánea, está también fundamentada en la posibilidad misma de asignar a la violencia (definida de un modo técnico) un lugar "atrás", en la reclusión (a veces aséptica) del "pasado". En otras palabras, en la medida en que las sociedades se mueven hacia adelante, la violencia va quedando confinada al atrás. Un "movimiento" que se presenta bajo la idea de una fractura imaginaria con un pasado violento y que instaura un momento de liminalidad colectiva. Me atrevería a decir que parte de los conceptos recibidos, y que estructuran nuestra vida cotidiana, se derrumban. Este "antes" y este "después", que definen en cierta medida el fundamento de diversas iniciativas enmarcadas como transicionales, son la esencia de lo que podríamos llamar la "promesa transicional". Este presupuesto fundacional es traducido a la sociedad través de una serie de dispositivos de fractura, que trazan, por decirlo así, dicha línea imaginaria. Los pilares de justicia, verdad, y reparación son los modos de codificación de esta idea. Como toda liminalidad, no nos jugamos el pasado, sino el porvenir: el futuro no habita adelante, sino en las condiciones de posibilidad del pasado como pasado.

Así, la noción de países en "transición" (porque sabemos que el proyecto transicional es un proyecto estado-centrista), instaura un movimiento teleológico, desde un estado de violencia a un estado de post-violencia, de la mano de los derechos humanos: es decir, una democracia liberal indefectible y paradójicamente insertada en las contradicciones del capitalismo contemporáneo. Es en esta teleología que acudimos al evangelio global del perdón y la reconciliación donde, en teoría, la enunciación pública de la verdad -a la manera de un evangelista, un confesionario o un psicoanalista de diván- nos libera. Lo que este modelo de relación con el pasado instaura -y valga decir que cuando sucede, lo hace a través de balances de poder muy complejos- es hacer inteligibles ciertas formas de violencia. Sin embargo, el problema no es lo inteligible (si indizamos numéricamente, por ejemplo) sino lo ininteligible, lo que no se logra (por razones epistemológicas y por razones políticas) leer como violencia, pero que está en el seno de nuestras violencias.

Sin embargo, en países donde desigualdades y diferencias se entrecruzan palpablemente, donde violencias crónicas de largas temporalidades (las que producen lo que llamo "daños históricos") han estructurado la vida cotidiana, esta "promesa" plantea una serie de preguntas importantes. Por cierto, sólo hay que ver los paros masivos en Buenaventura hace menos de dos años para vislumbrar lo que sería el derrumbe de la "promesa": el estado transicional, "reconciliatorio" y "perdonante" re-inscribiéndose (para usar una imagen típicamente kafkiana) a sí mismo a través de la violencia, entendida como el establecimiento del orden. Pero volvamos a las preguntas centrales: ¿es posible identificar en los escenarios transicionales una serie de "continuidades" más que de "rupturas”? ¿No deberíamos más bien hablar de una dialéctica entre fracturas y continuidades de la violencia? ¿Dónde y cómo tendríamos que situar la 
mirada para percibir esta dialéctica? Diversos autores han señalado las dificultades en aplicar, o incluso, de imaginar el prospecto de un futuro (post-violencia) en escenarios donde hegemonías políticas y económicas son, y continúan estando, enraizadas históricamente: Sudáfrica, Guatemala, Colombia, Salvador, e incluso el llamado "cuarto mundo," el del ser humano "aboriginalizado", incrustado en las opulencias del primero en Canadá, Australia, Nueva Zelandia, entre otros. A mi modo de ver, identificar estas tensiones en contextos concretos de aplicación tecnocrática es esencial, no sólo para comprender las posibilidades de la sostenibilidad de la paz (un término más diverso de lo que a veces se reconoce) sino para entender cómo individuos específicos y comunidades más amplias conectan el presente con procesos históricos de mayor profundidad, en un esfuerzo por recrear el futuro. Si no hacemos esto, ¿no estaremos entonces sembrando las semillas de futuras guerras? A veces me pregunto (en voz muy, muy baja) si la promesa transicional no es más que la utopía venida a menos, secuestrada por tecnicismos, acaso necesarios. Habitar la academia es tener un pie en estos dos mundos.

La reflexión sobre la naturaleza del "campo de estudios" sobre lo transicional, que constituye el centro de lo que he tratado de exponer, permite realizar una serie de cuestionamientos y hacer evidente la necesidad de entender la multiplicidad de dinámicas sociales que se gestan en momentos en que emerge la posibilidad de imaginar una otra sociedad (Gready, y Robins, 2014). Cuando digo "campo" llamo la atención de una superposición compleja: "campos académicos", "campos de fuerzas", y "campo", en sentido "antropológico". Por eso hablo de geo-políticas de la paz y lo transicional, de las relaciones entre el poder, el espacio y el conocimiento que llamamos "construcción de paz" o "promoción de la democracia", un "campo" creado, producto de la caída del llamado "campo socialista" y el muro de Berlín. Así, en medio de las múltiples transicionalidades que vive Colombia, -en donde simultáneamente vivimos la post-violencia paramilitar (con todo y sus continuidades), el post-conflicto con las FARC, y el conflicto armado con el ELN (por no mencionar las violencias crónicas e históricas)- la antropología tiene al menos un reto particular: imprimir una sensibilidad distinta a los procesos que emanan del Acuerdo de Paz, y lo que en la práctica significan. En otras palabras, tenemos que sumar al engranaje institucional (en todo caso, algo que por lo general los antropólogos añoran), y a su pluralización, a la vez que acompañar iniciativas y procesos sociales de largo aliento, más allá del dinero de la cooperación internacional y las culturas de la auditoria universitaria.

\section{III. ¿Y la antropología, qué?}

El otro reto, para mí el más importante, es crítico: desnaturalizar la "promesa” y "la teleología" transicional, atender a las continuidades de las viejas nuevas violencias, y problematizar el "evangelio global del perdón y la reconciliación", que instaura modelos del tiempo y del recuerdo (y hasta del olvido), formas de nominar la violencia, de performar la verdad públicamente y concepciones del daño a través de epistemologías legales, en tanto teorías del dolor colectivo. De cara a esto, creo que la antropología en Colombia (y me atrevería a decir, aunque de manera retrospectiva, que en América Latina también) está ante la tarea analítica de entender estos momentos complejos y sus trayectorias, en donde el "reconocimiento del dolor del otro" (lo que podría llamar la "víctima oficializada") cohabita con una tecnopolítica que, de alguna manera, lo domestica. Este reto viene de la mano, obviamente, de una indagación seria por ciertos aspectos del dispositivo transicional (aquí me distancio del discurso hegemónico de la justicia transicional): por ejemplo, las relaciones entre la "segurocracia (o el sector seguridad, como dicen algunos), la re-incorporación de combatientes y las nuevas subjetividades"; las "etnografías de la ley"; las conexiones entre la idea del "desarrollo, la transición y el capitalismo global", de donde emanan 
una plétora de contradicciones sociales que han dado al traste, en otros lugares, con la ilusión de la transición; los "estudios sobre la producción y la administración del pasado" y sus modos de indizar el tiempo; las "etnografías de las ruinas de lo social y su reconstitución". Y, finalmente, una reflexión sobre "las materialidades, los residuos y los desechos tecnológicos de la Guerra". En pocas palabras, atención a la historicidad del dispositivo transicional y sus modos globales de circulación de teorías, conceptos, prácticas asociadas y expertos.

Termino con una reflexión sobre la relación de lo político y lo sensible (Castillejo, 2016c). Creo que situarse en esta tensión, entre fracturas y continuidades, requiere una cierta integralidad, como parte de nuestras formas de habitar la academia y de entender su geopolítica; del oficio artesanal de hacer antropología. Lo digo sin querer herir susceptibilidades, porque de alguna manera todos lo hacemos. En general, pero sobretodo en la liminalidad de la transición, el trabajo intelectual implica saber escuchar (por autoevidente que suene): es decir, atender a los silencios y a sus contextos de enunciación, a la relación entre lo audible y lo inaudible como frontera de lo político. Debe, así mismo, saber escribir. Es decir, navegar entre el texto académico, el ensayo o la narrativa, a través de los sonidos o las imágenes visuales, sin perder el rigor, pero permitiendo la creatividad. Aquí se pone de presente nuestra capacidad para transmitir a otros, desde niños de escuela hasta super-expertos. Y finalmente, saber hablar en diferentes lenguas disciplinarias, en una suerte de poliglosia humanista.

Una iniciativa con espíritu colaborativo, transversal (incluso disciplinariamente) e integrativo, como valores centrales de nuestros modos otros de habitar el conocimiento, más preocupada por proponer una concepción plural de la paz, una "paz en pequeño", como le digo, y dispuesta a ser parte de la Imaginación Social del Porvenir. No sea que, frente al momento que nos ha tocado vivir, nos quedemos viendo, como dice el título de esta corta presentación, del ahogado, el sombrero.

\section{Segunda viñeta: (...) En la era de la administración de las víctimas}

Me llegó una tarde por correo electrónico, en el Urabá, la región más noroccidental del Departamento de Antioquia, cuna de muchas violencias. Acompañaba a un colega a realizar, con campesinos y diversos líderes, talleres sobre los acuerdos de Cuba (lo que se había negociado hasta ese momento), una especie de medida impromptu del establecimiento ante la indiferencia y la ignorancia generalizada del texto. La debacle del plebiscito del año siguiente, octubre del 2016, se sentía ya en los aromas del ambiente. Chigorodó, Mutatá, Apartadó, y Turbo (el lugar más ruidoso del mundo, posiblemente), entre residentes y resguardos indígenas, anduvimos (junto a los guardaespaldas) lo que pudimos en mi corta visita. Además de la belleza de la región, de su consabida historia paramilitar, sus movimientos políticos y de obreros sepultados a plomo limpio, Urabá es la dimensión desconocida cuando se le compara con el resto del departamento de Antioquia, caracterizado (en general) por una mentalidad de colonos "civilizadores", emprendedores y rezanderos de camándula. Urabá es como un patio trasero. Zona estratégica de tránsito entre el Pacífico chocoano y el Caribe colombianos, colindando a la vez con la frontera con Panamá en el Tapón del Darién, Urabá, como Buenaventura, se lee como otro polo de desarrollo. Sin embargo, éste era distinto.

A mi casillero de correo electrónico llega, a través de un contacto, el Power Point completo del proyecto de transformación radical de la región. Documento de circulación tan restringida que parecía un secreto de Estado. Del jardín trasero de Antioquia al prospecto de un puerto de alta tecnología. El llamado “Diamante Caribe: Apartadó, Turbo, Urabá Antioqueño. Proyecto Ciudad Territorio". Con 194 diapositivas y mapas, el documento puntualiza el "desarrollo" potencial de la región y su conexión con la globalización contemporánea, como lo hacen evidente las referencias a São Paulo, Ámsterdam, Menorca, Croacia, 
Barbados, entre otros. Con una sofisticada edición digital, lo que se muestra es la articulación de un concepto de riqueza e intercambio transnacional. La cara de la transición colombiana, sin que (al momento de recibirlo) se haya firmado un acuerdo definitivo.

Para tal efecto, los encargados se sientan a investigar, explorar y diseñar, hasta el más mínimo detalle, esta "ciudad-región". Fotografías aéreas actuales de cada ciudad, imágenes y renders elegantísimos de los posibles aeropuertos, puertos marítimos, grillas de carreteras primarias de futura construcción, sistemas de alcantarillado, conectividad digital, ambiental, y hasta prospectos poblacionales, se presentan en este complejo texto.

Aspectos demográficos, culturales, salubres, escolares, así como mapas de parcelas agrícolas debidamente clasificadas por área cultivable, proyectos de eco-canales, parques industriales, logísticos, aduanas, zonas francas, estructuras del transporte público, elementos del paisaje, hotelería, turismo, hacen parte de este doble ejercicio de leer lo que hay para construir lo que, parece, será la otra Urabá. Se nos vende un proyecto ecológico turístico "auto-sostenible", con fotografías idílicas de vacacionistas remando por los canales y las zonas acuíferas. Imágenes de palmeras, y atardeceres golpeando nostálgicamente con su luz sobre el agua, nos invitan a la nueva Colombia. Así mismo, fotografías de jóvenes madres blancas transitando en su pequeño ciclo-coche llevando a sus hijos sonrientes, presentan los senderos de caminata, evocando una libertad imaginaria y los contornos de la Colombia post-conflicto. Siempre, en mis escritos, he insistido mucho en que una transición es el momento en el cual una país moldea "una nueva sociedad imaginada". Pues las imágenes de este texto son una versión radical de esta imaginación. Se imagina la familia, el ocio, el intercambio, y se pinta una especie de Miami bananero o palmero (también por la presencia de grandes cultivos de palma africana y banano). Imágenes al mejor estilo de Dubái, con embarcaderos de botes y yates elegantes, como los que en alguna ocasión conocí en el puerto de aquel país del Golfo Pérsico. Imágenes en tres dimensiones, fotos satelitales, estudios de corrientes marinas, de vientos, y fotos de la actual Urabá: al respecto de los "paisajes del agua", la fotografía muestra una niña negra de trenzas remando una chalupa en medio de un río negruzco y un embarcadero en el fondo, con todo y su basura flotante. El del presente es un Urabá oscuro, negro, racializado, sucio, indio, violento. El del futuro es iluminado, claro, cristalino, esperanzador. Tal es el juego de oposiciones que opera como presupuesto semiótico, sobre el que se sitúan las fotos. El proyecto ciudad-territorio nos habla de la Agrópolis Urabá, en conexión con una ficcional Agrópolis Montería y la Agrópolis Sincelejo (ambas ciudades capitales), polos de la nueva "civilización". Centros de actividad paramilitar, de grandes latifundios y ganadería extensiva. En fin, podría seguir casi indefinidamente describiendo los mapas de conexiones regionales, el relieve, la hidrografía, las llamadas Metrópolis del Mar, los territorios intermedios, los estudios de isócronas, las ciudades y territorios diamante (cuyo nombre me recuerda la operación tipo "club campestre" de la medicina privada en Colombia y sus estratos socioeconómicos).

Dos cosas llamaron mi atención de este documento. Por una lado, el obvio nivel de detalle, a medio camino del proceso de paz. Pareciera que llevaran pensando esto por mucho tiempo. Como si la transición colombiana, la reincorporación de las FARC y el lenguaje de la reconciliación se hubieran convertido en un buen negocio. De nuevo, lo que la transición promete se le endosa al desarrollismo. Lo segundo es Buenaventura. A pesar de la violencia del Urabá (al punto que una de las mayores bandas de hampones heredados del paramilitarismo se llama los Urabeños) la de Buenaventura se ve infinitamente peor. Las casas de pique son epítomes del terror como forma de gubernamentalidad, como estructura de organización y extracción. La violencia de la post-violencia se demarca con esas casas (y hasta donde sé, con la ausencia de un proyecto de semejante envergadura como el Diamante) en una compleja tensión con esta otra transición, la de la Urabá soñada e imaginada. La violencia es, en cierta forma, epistemológica. 
El trazo de la línea imaginaria entre el pasado violento, el presente liminal, y el porvenir, se realiza con esa violencia epistemológica, acompañada de la literal, justo en el momento en que se erigen las administraciones de las víctimas como paradigma moral.

Recibido: 18 de agosto de 2017

Aprobado: 16 de enero de 2018

Revisión: Federico Lavezzo

\section{Referencias bibliográficas}

ABRAHAMSEN, Rita. 200o. Disciplining Democracy: Development Discourse and Good Governance in Africa. London and New York: Zed Books.

ANGHIE, Anthony. 2004. Imperialism, Sovereignty and the Making of International Law. Cambridge: Cambridge University Press.

BHTA, Nehal. 2008. "State-Building, Democratization and 'politics as technology". Social Science Research Network, (December). https://papers.ssrn.com/sol3/papers.cfm?abstract_id=1574349

CARROTHERS, Thomas. 2002. "The End of the Transition Paradigm". Journal of Democracy, 13(1): 5-21.

CASTILLEJO CUÉLLAR, Alejandro. 2017a. "Introducción. Dialécticas de la Fractura y la Continuidad: elementos para una lectura crítica de las transiciones" En: . (editor académico y compilador), La ilusión de la justicia transicional: perspectivas críticas desde el Sur Global. Bogotá: Editorial Universidad de los Andes, Facultad de Ciencias Sociales. pp. 1-58 . 2017b. "La Escala Humana de la Herida: Apropiaciones y traducciones del daño en Colombia". En: Mauricio Nieto (ed.), Colombia Contemporánea: Miradas Disciplinares Diversas. Bogotá: Universidad de los Andes. pp. 151-168 . 2016a. Poética de lo Otro: Hacia una Antropología de la Guerra, la Soledad y el Exilio interno en Colombia. Bogotá: Universidad de los Andes . 2016b. "El plebiscito como problema moral". En: E. Rueda, S.V. Alvarado; P. Gentilli (eds.), Paz en

Colombia: Perspectivas, Desafíos, Opciones. Buenos Aires: CLACSO. pp. 121-126. . 2016c. "La Biblioteca familiar". Revista Cronopio (Medellín), 68 (Abril 29), Sección Cronopio y

Sociedad. http://www.revistacronopio.com/?p=17999. Acesso: octubre 30 del 2018. . 2015. "La Imaginación Social del Porvenir: reflexiones sobre Colombia y el prospecto de una Comisión de Verdad" En: Alejandro Castillejo Cuéllar et al., Proceso de paz y perspectivas democráticas en Colombia (1a ed.). Buenos Aires: CLACSO. pp 13-73 . 2014. "La Localización del daño: etnografía, espacio y confesión en el escenario transicional Colombiano". Horizontes Antropológicos, 20(43): 213-236. . 2013. "Voces [en la cabeza]: espacialidad, confesión y las mediaciones tele-tecnológicas de la Verdad". Papeles del Centro de Estudios de la Identidad Colectiva CEIC, Universidad del País Vasco, 92(1): 1-42. CHANDLER, David. 2006. Empire Denial: the Politics of State Building. London and Ann Arbor (MI): Pluto Press.

DEMMERS, Jolle; FERNÁNDEZ JILBERTO, Alex; HOGENBOOM, Barbara. 2005. Good Governance in the Era of Global Neoliberalism. London and New York: Routledge.

DOORNBOS, Martin. 2006. Global Forces and State Restructuring: Dynamics of State Formation and Collapse. London and New York: Palgrave. 
GILMAN, Nils. 2003. Mandarins of the Future: Modernization Theory in Cold War America. Baltimore and London: The Johns Hopkins University Press.

GONZÁLEZ, Roberto. 2010. "Indirect rule and embedded anthropology: practical, theoretical and ethical concerns”. En: J. Helly, S. Mitchell, Jauregui, J. Walton (eds.) Anthropology and global counterinsurgency. Chicago: Chicago University Press. pp. 231-243

GREADY, Paul; ROBINS, Simon. 2014. "From Transitional Justice to Transformative Justice: a new agenda for practice". The University of York, Center for Applies Human Rights, Briefing Note TF-01, (June): 1-5. http:/| www.simonrobins.com/Transformative\%20Justice\%2oBriefing\%20Paper.pdf. Acesso em: octubre 30 del 2018.

GUILHOT, Nicolas. 2005. The Democracy Makers: Human Rights and the Politics of Global Order. New York: Columbia University Press.

KEENE, Edward. 2004. Beyond the Anarchic Society. Grotius, Colonialism, and Order in World Politics. Cambridge: Cambridge University Press.

LEY 70 DE 1993 (agosto 27) Diario Oficial No. 41.013, de 31 de agosto de 1993.

LETHAM, Michael. 2003. Modernization as Ideology: American Social Science and "Nation Building" in the Kennedy Era. Chapel Hill and London: University of North Carolina Press.

MITCHELL, Timothy. 2002. Rule of Experts: Egypt, Techno-Politics, Modernity. Berkeley and London: University of California Press.

MUNARRIZ, Gerardo. 2008 "Rhetoric and Reality: The World Bank Development Policies, Mining Corporations, and Indigenous Communities in Latin America". International Community Law Journal, 10: 431-443.

NUGENT, David. 2010. "Social Science Knowledge and Military Intelligence: Global Conflict, Territorial Control and the Birth of Area Studies during WWII". Journal of World Anthropology Network, 1(3): 31-58.

Ó TUALHAIL, Gearóid; DALBY, Simon. 1998. Rethinking Geopolitics. London and New York: Routledge. PAREKH, Bhikhu. 1993. "The cultural particularity of Liberal Democracy". En: David Held (ed.), Prospects of Democracy: North, South, East, West. London: Polity Press. pp. 156-175.

RICHMOND, Oliver (ed.). 2010. Peace Building:Critical Developments and Approaches. London and New York: Palgrave.

SCHUTZ, Alfred; LUCKMANN, Thomas. 2003. Las estructuras del mundo de la vida. Buenos Aires: Amorrortu Editores.

SRIRAM, Chandra. 2007. "Justice as Peace? Liberal Peace Building and Strategies of Transitional Justice". Global Society, 21(4): 579-591.

\footnotetext{
Alejandro Castillejo Cuéllar

Profesor Asociado, Departamento de Antropología, Director del Programa de Estudios Críticos de las Transiciones (PECT) https://curlinea.uniandes.edu.co/alejo_castillejo/antropographias/index.php/ esdt de la Universidad de los Andes, Colombia. Actualmente es co-investigador en los proyectos internacionales: Changing the Story: Building Inclusive Societies with Young People in 5 Post-Conflict Countries https://changingthestory.leeds.ac.uk/profiles financiado por el Arts and Humanities Research Council (Inglaterra) y Desapariciones: Estudio en perspectiva transnacional de una categoría para gestionar, habitar y analizar la catástrofe social y la pérdida (España). http://identidadcolectiva. es/victimas-desapariciones/que-es-mundos-de-victimas/proyecto-desapariciones/\# https://orcid.org/oooo-0002-6441-6609

E-mail: acastill@uniandes.edu.co
} 